Monográfico / Monographic

\title{
Capitalismo creativo. Cambios en los factores productivos, las agencias, los discursos y las políticas
}

\author{
Creative Capitalism. Changes in the Productive Forces, Agencies, \\ Discourses and Policies
}

\author{
José Angel Bergua Amores (iD \\ Universidad de Zaragoza, España. \\ jabergua@unizar.es \\ Recibido / Received: 27/04/2020 \\ Aceptado / Accepted: 27/06/2020
}

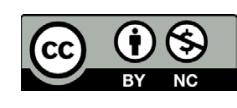

\section{RESUMEN}

La importancia de la creatividad en la economía contemporánea está relacionada con un incremento de la desigualdad. Se puede explicar esta relación utilizando el concepto de explotación marxista, pero entendiendo que admite tres variantes. El capitalismo industrial explota la fuerza de trabajo aportada por el proletariado en tanto que agencia y genera discursos basados en metáforas sólidas y la lógica de la jerarquía. El capitalismo postindustrial explota la vida ordinaria o bios depositada en la multitud y sus discursos se basan en metáforas líquidas y el papel de la anarquía. El capitalismo creativo explota lo indeterminado que contiene lo imaginario, esgrime discursos gaseosos y da importancia a lo transfinito.

Palabras clave: imaginario; espíritu; transducción; multitudo.

\begin{abstract}
The importance of creativity in the contemporary economy is related to an increase in inequality. This relationship can be explained using the Marxist concept of exploitation but understanding that it supports three variants. Industrial capitalism exploits the labor force provided by the proletariat as an agency and generates discourses based on solid metaphors and the logic of hierarchy. Post-industrial capitalism exploits the ordinary life or bios, deposited in the crowd or multitudo, and its discourses are based on liquid metaphors and the role of anarchy. Finally, the creative capitalism exploits the apeiron or indeterminated that contains the imaginary, uses gaseous discourses and gives importance to the transfinite reality.
\end{abstract}

Keywords: imagery; spirit; transduction; multitudo. 


\section{INTRODUCCIÓN}

La creatividad tiene que ver con la aparición de algo nuevo, por lo tanto, imprevisto, impulsado por la actividad de cualquier clase de agente individual o colectivo (Bergua, 2017a, p. 423). Por lo tanto, de la actividad creativa no puede resultar sino el "acontecimiento" tal como lo interpreta Badiou (1990, p. 76), ya que su novedad suspende la validez de las instituciones encargadas tanto de conceder sentido como de facilitar la administración de las cosas y, en consecuencia, hace que "lo admisible" deje de valer" (Badiou, 1990, p. 76). Si, para el filósofo francés, "solo desde la perspectiva del acontecimiento se puede hacer justicia al exceso del ser" (Badiou, 1999, p. 317), en términos sociológicos se podría decir de la creatividad que el exceso que trae consigo lo es de lo social en relación a la sociedad tal cual está instituida. El problema de las ciencias en relación a la creatividad así entendida consiste en que, si aquéllas hacen comprensibles los fenómenos proporcionando sentido, reduciendo la incertidumbre y facilitando la previsión, un acto de creatividad, por el hecho de traer consigo una novedad que antes era imprevista (e inadmisible), pone precisamente en el foco de su reflexión aquello a lo que la ciencia nunca puede llegar (Taleb, 2008). La creatividad tiene entonces que ver con lo imposible y la única manera de que cualquier tipo de conocimiento esté a tal altura es que reconozca su propia finitud y admita que no sabe. En el ámbito de las ciencias duras han permitido alcanzar esta ignorancia distintas clases de "avances", entre otros el "principio de incertidumbre" (Heisenberg, 1988, pp. 14-15) o el "teorema de la incompletitud" de Gödel (Goldstein, 2005, pp. 148-150). En las ciencias blandas, aunque la ignorancia positiva está muy cerca de principios como el "relativismo cultural" o el "etiquetaje diferencial", solo el psicoanálisis la ha introducido en el corazón mismo de su reflexión. Esto era inevitable después de haber concluido que la parte inconsciente y no racional del sujeto, incluido el científico, por supuesto, es la más importante.

Por todo lo anterior, la creatividad es muy diferente de la innovación, siempre planeada y dirigida a ciertas metas ya decididas o enmarcadas de antemano en términos de utilidad, las más de las veces económica. Aunque desde Roma hasta los inicios de la Modernidad, pasando por el Cristianismo, la innovación siempre tuvo connotaciones negativas, por asociarse, respectivamente, a cambios de costumbres, revoluciones políticas y herejías religiosas, todas ellas imposibles de aceptar, desde mediados del siglo XIX el término pasó a referirse a ciertos cambios tecnológicos y científicos positivamente connotados (García, 2012). Con este nuevo sentido, la innovación saltó a la economía de la mano de Schumpeter cuando se refirió a los procesos de "destrucción creadora", en los que, además de sepultarse lo viejo, irrumpen emprendimientos que traen consigo cambios en los procesos productivos y en los propios productos (Castro Martínez y Fernández de Lucio, 2013, pp. 13-23). Sin embargo, esta aceptación económica de la innovación ha ido acompañada de la pérdida de relación con lo imposible, pues solo es solicitada para aportar utilidades

¿Es posible que la creatividad haya desembarcado en la economía para recuperar ese trato con lo extraño o imposible que la innovación ha perdido? Una prueba de esto podría ser que desde comienzos del siglo XX hasta 1974, con la "innovación" todavía muy viva, solo están documentados 46 usos del término castellano "creatividad" en 16 documentos, mientras que, a partir de 1983 el nuevo término es introducido en el Diccionario Manual de la Real Academia de la Lengua Española y comienza a ser usado de un modo cada vez más masivo (Marimón, 2020). Algo parecido ocurre con la palabra inglesa inglés creativity, registrada en el Oxford English Dictionary desde 1875, pero que solo comienza a ser operativa en investigación desde 1950. Y un mismo despegue de su uso experimenta el vocablo francés créativité desde el año 1970. 


\section{Creatividad y desigualdad}

Al margen de lo anterior, una de las más llamativas características de la nueva economía creativa (Howkins, 2005; Florida, 2002) es su íntima relación con la desigualdad, pues de las 10 ciudades más creativas de Estados Unidos 5 de ellas son las que tienen mayor desigualdad y entre las 10 ciudades menos creativas hay 4 con menores desigualdades (Florida, 2002). Por lo que respecta a España, en el 2001 y el 2011 el volumen de la clase creativa ha aumentado en todas las comunidades autónomas, siendo inmune a la crisis del 2008 y estableciendo desde entonces una relación directamente proporcional con el crecimiento de la desigualdad (Bergua et al., 2016).

Florida (2017) sugiere que, en el contexto de la economía creativa, el problema de la desigualdad en un territorio viene dado por el hecho de que los más altos ingresos de las clases creativas son suficientes para pagar los también más altos gastos relacionados con la vivienda, tanto en las ciudades como en las áreas metropolitanas, frente a las clases de servicios y manufactureras que son expulsadas fuera de tales territorios' ${ }^{1}$. Sin embargo, Piketty (2014) diría que la desigualdad tiene que ver con una importante característica del sistema económico: la tendencia a que el rendimiento del capital aumente a un ritmo superior de lo que lo hace el crecimiento económico. Sin embargo, Acemoglu y Robinson (2012), sugieren que la prosperidad de la parte alta de la estructura social no depende de la mayor rentabilidad del capital, sino de los valores, culturas y entramados institucionales que favorecen la competencia y la propiedad, ya que, si no funcionan, automáticamente aparecen "élites extractivas" que se apropian de la riqueza, incrementan la desigualdad y empobrecen la sociedad. Por su parte, De Soto (2000), tras comprobar que el capital está más extendido por el conjunto de la estructura social de lo que parece, pues, en Egipto, por ejemplo, hasta el $47 \%$ de los ingresos de los llamados "trabajadores" proviene de un capital que es informal, ya que no está registrado, sugiere que el auténtico problema del capitalismo del siglo XXI no es solo la desigualdad, sino el conjunto virtual y vacío formado por los papeles sin respaldo en bienes que padece Occidente y los bienes sin papel que sufre el resto del mundo.

Más allá de las causas concretas y cuantificables que vinculan la creatividad y la desigualdad, propongo prestar atención a las características principales y más profundas de esta modalidad de capitalismo en comparación con otros dos que le anteceden, el industrial y el postindustrial (García, 2014). Si bien todos ellos mantienen el hecho de que el capital es el factor productivo dominante, cambian aquellos otros factores que producen valor y con los que el capital establece relaciones preferentes de explotación. También cambia la agencia en la que dicho factor se encarna y el concepto que en términos analíticos habla de esa agencia. Del mismo, se transforma el afuera con el que el sistema trata, tanto para protegerse como para alimentarse. E igualmente cambian los discursos y campos semánticos, con sus correspondientes metáforas, levantados sobre cada concepto y las características principales de las prácticas políticas con la que dichos discursos se relacionan. No obstante, conviene subrayar que los tres tipos de capitalismo, aunque sean diferentes, no se excluyen, pues el primero no ha desaparecido con la llegada del tercero y la importancia que el espíritu, como veremos, tiene en este, ya era patente en el primero, como demuestran el interés de Marx por el carácter fetichista o fantasmal de la mercancía en el plano analítico y la afirmación política de que el espectro del comunismo vagaba por Europa buscando un agente social en el que encarnarse. Del mismo modo, algunas características del capitalismo creativo ya se insinúan en la sociedad del conocimiento y de la información, la cual ni mucho menos desaparece cuando se vuelven hegemónicas la creatividad y su economía. Por lo tanto, no nos vamos a referir tanto a fases o estadios que se suceden en el tiempo como a vectores que ganan o pierden intensidad y hegemonía.

1 Una crítica a esta conclusión puede verse en Donegan y Lowe (2008). 
Cuadro 1. Tipos de capitalismo

\begin{tabular}{|c|c|c|c|c|c|}
\hline & $\begin{array}{c}\text { FACTOR QUE } \\
\text { PRODUCE VALOR }\end{array}$ & $\begin{array}{l}\text { AGENCIA QUE } \\
\text { LO SOSTIENE }\end{array}$ & $\begin{array}{l}\text { CONCEPTO } \\
\text { ANALÍTICO- } \\
\text { POLIITICO }\end{array}$ & $\begin{array}{l}\text { AFUERA } \\
\text { INDETER- } \\
\text { MINADO }\end{array}$ & $\begin{array}{c}\text { METÁFORAS (Y } \\
\text { POLIITICAS) }\end{array}$ \\
\hline $\begin{array}{l}\text { capitalismo } \\
\text { Industrial }\end{array}$ & Trabajo & Proletariado & Clase & $\begin{array}{c}\text { Ej. } \\
\text { Cuidados, } \\
\text { monedas } \\
\text { locales, etc. }\end{array}$ & $\begin{array}{l}\text { Sólidas } \\
\text { (jerarquía) }\end{array}$ \\
\hline $\begin{array}{c}\text { capitalismo } \\
\text { de la } \\
\text { información y } \\
\text { del } \\
\text { conocimiento }\end{array}$ & $\begin{array}{l}\text { Sociabilidad y } \\
\text { comunicabilidad }\end{array}$ & $\begin{array}{l}\text { Vida ordinaria } \\
\text { y cotidiana }\end{array}$ & $\begin{array}{l}\text { Multitud } \\
\text { (bios) }\end{array}$ & $\begin{array}{c}\text { Ej. } \\
\text { Internet } \\
\text { profundo, } \\
\text { Criptomonedas } \\
\text { (bitcoin, } \\
\text { ethereum), etc. }\end{array}$ & $\begin{array}{l}\text { Líquidas } \\
\text { (anarquía) }\end{array}$ \\
\hline $\begin{array}{c}\text { capitalismo } \\
\text { de } \\
\text { la creatividad }\end{array}$ & $\begin{array}{c}\text { Lo } \\
\text { indeterminado }\end{array}$ & Imaginario & Espíritu & $\begin{array}{c}\text { Ej. } \\
\text { Producción de } \\
\text { modas en las } \\
\text { calles }\end{array}$ & $\begin{array}{c}\text { Gaseosas } \\
\text { (transfinitud) }\end{array}$ \\
\hline
\end{tabular}

Fuente: elaboración propia.

\section{Clases y jerarquías}

El primer capitalismo, coincidente con el auge y apogeo de la sociedad industrial (desde mediados del siglo XVIII en el Reino Unido hasta mediados del siglo XX en EEUU), en la que el sector secundario fue dominante o determinante, tiene que ver en gran medida con el que teorizara Marx. El trabajo es el factor productivo que realmente añade valor y resulta explotado, debido a que la fuerza productiva dominante, el capital, le impone una relación de intercambio desigual, ya que da menos de lo que recibe, por lo que le extrae un plusvalor. Conviene añadir que en este capitalismo el capital subsume un trabajo, que inicialmente es exterior al sistema y le proporciona ciertas habilidades y competencias, pero que, con posterioridad, sin que desaparezca del todo esa exterioridad, pasará a ser producido desde las entrañas mismas del sistema (Marx, 1971). Por otro lado, a todas las explotaciones y subsunciones (formal y real) del trabajo, acompañan procesos de (re) apropiación y producción de valor de carácter colectivo, no privado, algunos de los cuales hunden sus raíces en formas económicas precapitalistas o ajenas al capitalismo, como ocurre con los bienes comunes, las economías de los cuidados, los bancos del tiempo, las monedas locales, las empresas recuperadas y otras prácticas similares que aparecen o simplemente se hacen más visibles en tiempos de crisis para afrontar lo que el sistema no quiere, puede o sabe resolver (Laval y Dardot, 2015). El marxismo clásico también se refiere al proletariado como la agencia que sostiene al trabajo y a la que, ya en términos políticos, se le adjudica la posibilidad y responsabilidad de cambiar el sistema.

El concepto que mejor canalizó todas estas implicaciones fue el de clase. Sin embargo, ha experimentado tantas interpretaciones como la realidad que trataba de circundar. Al contenido económico de la relación entre clases mediada por la explotación o intercambio desigual que descubrió Marx, se añadieron las desigualdades de poder y de instrucción (Wright, 1994), más tarde las simbólicas y luego también se consideraron las de género, edad y etnia, etc. ${ }^{2}$ Por otro lado, la extensión e intensificación de la explotación ha hecho

2 Pero es que el propio Marx contribuyó al despeñe de las clases al descubrir que, con la aparición de las sociedades anónimas y la disociación del binomio propiedad - gestión, resulta que el factor trabajo lo poseen tanto las posiciones más bajas como las altas (pues los gestores también son asalariados) y el capital está tanto en las más altas como en las bajas (pues los trabajadores también pueden ser accionistas), por lo que se deshace la vinculación biunívoca entre gentes y factores productivos, lo cual debiera tener alguna consecuencia en el discurso político, pues desaparece un enemigo exterior claramente definido, ya que cada sujeto pasa a llevarlo en su interior (Véase El Capital. Libro III. Capítulo XXVII, hay versiones completas en Internet; por ejemplo, en 
aparecer el "precariado" (Standing, 2011), término que incluye a los trabajadores temporales, a los contratos a tiempo parcial, a los becarios, al denominado "trabajo en masa" que se realiza por Internet, a los parados y subempleados aparecidos con la deslocalización de los trabajos poco cualificados, a la aparición de los interinos en el ámbito de la gerencia, cada vez más alejados del vértice superior de la estructura social, etc. Todo este mosaico de ocupaciones forma una gran y heterogénea clase emergente caracterizada por los bajos salarios, la pérdida de derechos políticos, civiles, sociales y económicos y, en general, la inseguridad. A esta difuminación de la clase que reconocen los analistas críticos ${ }^{3}$ ha acompañado un movimiento parecido impulsado desde el lado de los conversos, también con sus implicaciones políticas. Esto ocurrió cuando, en el plano sociológico, se decidió diferenciar a las gentes en clases sociales relacionadas con la profesión y el sector económico en el que se desenvolvían, como hizo Goldthorpe (1993) con su distinción de 10 clases. Lo mismo hizo el neoliberalismo político

Pasando al plano retórico, la noción de "clase" y las explicaciones que desde ella se esgrimen apelan a metáforas sólidas, como la de "estructura", a partir de las cuales resulta difícil, paradójicamente, como ya experimentó cierto marxismo, dar cuenta del cambio y encabalgarse a él. La razón es que esas metáforas dibujan estados, acciones, formas organizativas y principios políticos todos ellos cercanos al equilibrio, cuya forma se parece a la del inmutable cristal (Atlan, 1990), que impide cualquier clase de transformación. Es lo que ocurre con las formas organizativas "partido político" o "Estado" y la consecuente acción jerárquica basada en la obediencia que en todos los casos se promueve.

\section{Bios líquido}

El segundo capitalismo, relacionado con la sociedad de la información y del conocimiento, antaño denominada postindustrial y que arranca a mediados del siglo XX en EEUU, nos descubre que un nuevo factor productivo, precisamente la información y/o conocimiento, es el productor principal de valor y objeto preferente de explotación. Dicho factor es social o colectivo, pues depende de las acciones combinadas de diferentes agentes, del mismo modo que también eran sociales las competencias y habilidades del trabajo en el capitalismo anterior. Igualmente, como también sucedía entonces, las informaciones y conocimientos son inicialmente incorporados al sistema desde el exterior, pero luego son directamente producidos por él, creándose así una autopoiesis o retroalimentación de inputs y outputs que permitirá al orden social correspondiente autoproducirse.

Lo que en un principio el nuevo capitalismo incorpora y luego se produce como input son las sociabilidades primarias y las habilidades comunicativas básicas (Virno, 2003)5. Inicialmente todas ellas estaban y están inscritas en la vida ordinaria de las gentes. Con posterioridad, se pasó a implementar medidas para gestionarla, como ocurre con las políticas de recursos humanos en las empresas desde que Elton Mayo descubriera las relaciones informales, y más tarde se procedió directamente a producirlas. Sin embargo, este capitalismo aprovecha este nuevo valor más por la vía del consumo que de la producción, pues obtiene de los consumidores o usuarios de cualquier producto o servicio una valiosa información sobre sus hábitos que luego utilizará no solo para mejorar su oferta sino para para venderla y obtener beneficio. Esa información que cae en las manos

http://www.javiercolomo.com/index_archivos/Literatura/Marx/Marx.pdf).

3 Véase también Gaggi y Naduzzi (2006)

4 En 1954 Daniel Bell (2006) constató que los sectores económicos terciario, cuaternario y quinario eran cualitativa y cuantitativamente más importantes que el secundario. Más tarde diversos autores, Castells (1996) entre ellos, comenzaron a referirse a la información y el conocimiento como nuevos y relevantes factores productivos

5 Del mismo modo que ocurre con la información y el conocimiento primarios, que están inscritos en las comunicaciones y sociabilidades ordinarias, también la ciencia y la tecnología dependen de distintas redes de cooperación y confrontación colectiva (Latour, 1992). 
del capital es pues un plusvalor (Mason, 2016). Esta importante característica del segundo capitalismo, del mismo modo que ha ocurrido con el primero, no solo no ha desaparecido con la llegada del tercero, que más adelante veremos, sino que ha intensificado sus características. En efecto, las grandes plataformas, (Google, Facebook, Uber, etc.), aunque tienen un tamaño pequeño y en Estados Unidos apenas emplean al 2,5\% de la fuerza laboral, 4 veces menos que el sector manufacturero, tienen un peso económico enorme, tanto en términos cuantitativos como cualitativos (Srnicek, 2018). La materia prima de esta economía son ya directamente las vidas de los usuarios, ahora registradas en datos que posteriormente son refinados y ofrecidos a la publicidad (económica y política) y al propio Estado para mejorar las cuentas, obtener más votos e incrementar el poder. Si el $96 \%$ de los beneficios de Google y el $89 \%$ de Facebook vienen precisamente de la publicidad, aún habría que añadir los obtenidos por el trato clandestino y opaco que establecen con los servicios de inteligencia y policías estatales ${ }^{6}$. La plusvalía se extrae, por lo tanto, de los estilos de vida digitales de las gentes y vuelve ellas a través de productos o servicios y políticas diseñados con la información y conocimiento obtenidos, co-construyéndose así dicho bios, lo cual termina creando un ciclo autopiético formalmente idéntico al de la subsunción real del trabajo en el primer capitalismo.

La agencia que produce el nuevo valor no es ya ninguna clase social sino la vida social misma en su más absoluta elementalidad. Por eso resulta pertinente hablar de bioeconomía (Fumagalli, 2010), ya que se apropia y (re)produce el bios, la vida en su nivel social más básico, distinta de la zoe, una vida animal más elemental todavía, pues precede y excede a lo social. A la bioeconomía acompaña una biopolítica (Agamben, 1998) que ordena directamente la vida de la especie ocupándose de su nutrición, morbilidad, salud, etc. intentando extraer el máximo de utilidad e inocular la máxima obediencia. De todas formas, como ya sucedía en el capitalismo anterior, a todas las explotaciones, producciones y regulaciones de este nuevo factor productivo, acompañan procesos de (re)apropiación y producción de bios disidentes, en la mayor parte de los casos utilizando idénticos o similares dispositivos que los órdenes instituidos, pero dándoles usos perversos o subversivos. Las comunidades inteligentes de Internet (responsables de fenómenos como Wikipedia y distintas clases de hackeos o pirateos) son un buen ejemplo de esto, pues van justo en la dirección contraria que el negocio big data, a pesar de desenvolverse en el mismo hábitat. Forman parte también de esa exterioridad la Red Profunda, que incluye los sitios que los buscadores no son capaces de indexar, e igualmente una "red oscura" por la que el navegador TOR (The Onion Router -el "router cebolla"-) no deja rastro y garantiza así la privacidad e invisibilidad de los usuarios, entre los que se cuentan desde los activistas de Wikileaks a los amantes del anonimato pasando por traficantes de armas, drogas, etc. El tamaño de la red oscura en sus dos modalidades es muy superior al de la Nube, pues se sospecha que el $96 \%$ de la actividad tiene lugar en esa penumbra. En ese lugar invisible hay un trato con la información que no siempre forma parte del orden instituido y en el que se incuban resistencias, perversiones y subversiones de distinto tipo y difícil calificación política. Una de esas resistencias está precisamente en el origen de criptomonedas, como el Bitcoin o Ethereum (Arroyo, Díaz y Hernández, 2019, p. 11). La primera de ellas nació como consecuencia de la ingeniosa resolución de dos problemas. Primero, el de emular la no trazabilidad del dinero físico, que circula cambiando de propiedad sin que su valor se resienta, lo que se consiguió a base de criptografía, un recurso muy común desde los años 80 del siglo pasado en diversos movimientos, entre ellos los cypherpunks. El segundo problema fue sustituir al banco en su función de otorgar confianza a la interacción, así como de garantizar que el dinero que ha cambiado de manos no pueda volver a ser

\footnotetext{
6 El tratamiento de la descomunal cantidad de información producida, en torno a 2,5 millones de terabytes cada día (Holmes, 2018), se hace a través de algoritmos que descubren y predicen patrones y anomalías en el comportamiento colectivo, trabajo que se ve favorecido por la producción de transistores cada vez más baratos, producidos a mayor escala y cuyas prestaciones se duplican cada 18 meses.
} 
utilizado por el propietario original, lo cual se hizo introduciendo un ingenioso protocolo que vincula no solo a los usuarios involucrados, sino al resto, pues deben registrar las transacciones realizadas generando bloques de datos que verifican la conformidad de las transacciones y que se incorporan a los bloques existentes, recibiendo como recompensa cierta cantidad de criptomoneda. El asunto de la recompensa es importantísimo porque, además de involucrar a los usuarios en la verificación, eliminando así las instancias externas, logra que la criptomoneda, como ocurre con la fiduciaria, sea escasa. Pero es que la tan preciada escasez no solo deriva en la suculenta recompensa del minero, que el año 2018 ascendía en España a 20000 euros por bloque, sino también del consumo energético que exige el minado y la consiguiente creación de nueva moneda, que el año 2017 ya era superior al consumo de energía de hasta 159 países. Este freno o límite energético también permite luchar contra la especulación, otro de los objetivos de la criptomoneda. Pero para cumplirlo mejor se añade un mecanismo deliberadamente deflacionario consistente en disminuir la recompensa en dinero una vez alcanzada cierta cantidad de bloques, a la cual se llega al cabo de aproximadamente 4 años.

Además del bios, un concepto clave que da cuenta del nuevo actor interviniente en el segundo capitalismo, es la "multitud" (Hardt y Negri, 2000; Virno, 2003), ya no compuesta por individuos similares, como ocurría con las clases y las masas. El concepto fue inicialmente propuesto por Spinoza en el siglo XVI frente a la idea de "pueblo", utilizado por Hobbes para encontrar el fundamento de la soberanía. El primero entendía que la vitalidad política y económica de una sociedad no dependía de concepciones homogeneizadoras o uniformizadores, como sugería el autor inglés, a la postre vencedor en esta disputa, sino de la heterogeneidad y dinamicidad de las gentes, tal como mostraba su país, Holanda, en aquella época.

Tanto las explicaciones sobre el nuevo capitalismo como de las propias luchas que engendra y el nuevo agente que las canaliza, la multitud, remiten a un campo semántico repleto de metáforas líquidas (Bauman, 1997), pues hay abundantes referencias a redes, movimientos, circulaciones, fluidos, etc. Todos esos términos dibujan situaciones alejadas del equilibrio (Dupuy, 1992; Prigogine y Stengers, 1990) en la que las relaciones jerárquicas o centradas en un punto fijo exógeno, sea físico (el Estado y sus variantes en tanto que monopolizadores del uso de la sanción y obediencia) o cultural (creencias como Dios, la Revolución, etc. de las que derivan el resto de ideas y/o valores), ceden paso a una más amable versión de los puntos fijos exógenos (que dan lugar a totalidades en las que resulta imposible aceptar que los cursos de acción y sentido partan de un único centro y alcancen sin problemas a las gentes hasta convertirlas en conjuntos homogéneos, como ocurría con los conceptos analíticos y políticos utilizados por el capitalismo anterior) donde la anarquía (etimológicamente -an-arjé- ausencia de centro o fundamento) se hace un importante hueco, tal como sucede en los movimientos sociales (en lo político) y ciertas empresas (en lo económico) organizadas en redes. En general, en estos nuevos contextos los componentes de subjetivación y las sociabilidades ya no se administran paternal o despóticamente desde arriba, sino que circulan horizontalmente. El arquetipo que inspira estos tipos de acción colectiva ya no es pues el Padre sino la Fratria, todavía no pensada con profundidad al margen del propio Padre y de la anamnesis de la Madre. La excepción más notable respecto a este descuido es Ortiz-Osés (1993).

\section{Espíritu transfinito}

Finalmente, podemos hablar de un tercer capitalismo relacionado con el uso y explotación de la creatividad (Mould, 2019), convertida ya en el más importante factor productivo, pues, según los pronósticos de Florida (2002), en Estados Unidos iba a ser el 
mayor responsable de la producción de valor desde el 2014. Dicha creatividad está presente tanto en el propio proceso de producción como en la publicidad y gestión de las marcas, asociadas a sublimes cualidades espirituales que resultan enormemente rentables, incluso bastante antes de que Florida y otros "descubrieran" el carácter creativo del nuevo capitalismo. Téngase en cuenta que cuando Phil Morris compró Kraft en 1988 pagó por ella 12.000 millones de dólares, seis veces su valor "real" (Klein, 2001, p. 36), y que ya en los años 90 se estimó que entre la mitad y las dos terceras partes de la actividad económica tenía este carácter especulativo (Khor, 2001, p. 79). También se incluye en el capitalismo creativo esa explotación y (re)producción de experiencias, asociadas tanto a bienes y servicios clásicos como a otros nuevos, en las que lo importante son los componentes ideoafectivos movilizados (Pine y Gilmore, 2000). Los shoppings, malls, parques temáticos y el turismo forman parte de ello (Verdú, 2003). Igualmente absorbe este último capitalismo un amplio abanico de industrias culturales cuyos productos (música, cine, series, libros, artes, etc.) satisfacen la imaginación del sapiens mucho más que los servicios y las manufacturas ${ }^{7}$, hasta el punto de que presionan a estos para que envuelvan sus "cosas" con el mismo o similar aura ${ }^{8}$. En este nuevo capitalismo en el que la vida se vuelve gaseosa hay también lugar para esa economía de productos descargables sin límite alguno, que dejan de ser escasos, pierden el carácter sustractivo de los bienes de antaño, ya que no se gastan, y generan una disponibilidad absoluta en la que los precios se fijan al margen de la oferta y de la demanda (Mason, 2016). Ocurre lo mismo con la proliferación de créditos, hipotecas, tarjetas, etc. que los bancos utilizan para financiarse (ya que ni las empresas ni los Estados acuden ya a ellos, debido a que prefieren visitar los mercados), pues con esas ventas crearán productos financieros derivados que generarán altísimos beneficios especulando con el hecho de que no se devolverá el dinero inicialmente pactado (Pettifor, 2017). El componente gaseoso sobre el que flota esta desmaterializada economía son los climas de confianza y desconfianza, tan volubles e inestables que, en un instante, pueden pasar de proporcionar grandes beneficios a evaporarlos. También hay que incluir en este nuevo capitalismo su habilidad para convertirse en cultura. En efecto, el emprendimiento es ya un valor que se inculca en la educación primaria y las técnicas de coaching utilizadas para los directivos han desplazado a las antiguas terapias. También se han "traducido" e incorporado las culturas underground de los años 70, que combinaban drogas, música, crecimiento personal, amor libre, naturaleza, etc. (Sadin, 2018) y que han dado lugar a un nuevo "espíritu", bien distinto del que impuso la ética protestante (Boltanski y Chiapello, 2002). Si bien esas sociabilidades estaban presentes desde hace décadas, es ahora cuando parecen encontrar el mejor entorno para estimular la economía. Finalmente, forma parte también de este capitalismo esa Nube sobrecalentada que destila no solo datos sino más bien climas y atmósferas producidas por los millones de "likes", fakes, etc., da igual que sean humanos o artificiales, unas veces producidos por esos intermediarios de lo alto o de lo bajo que son los influencers, y otras veces generados directamente por las sinergias de la propia totalidad.

En general, todos estos cambios han pasado a explotar la emoción, esa "energía interna" que impulsa cualquier clase de acto dándole cierto "carácter" o "colorido" (Illouz, 2007, p. 15). No obstante, aunque sea en este siglo cuando el capitalismo emocional ha despegado, es realmente a principios del siglo XX cuando se incuba y nace. En efecto, es entonces cuando arranca el "estilo terapéutico", preocupado por la vida emocional y el desarrollo de técnicas específicas para tratarla. Este interés por los afectos se trasladó a los ambientes

7 Las impresiones que genera la cultura son básicas para la supervivencia individual, pues sin ellas no podría vivir ni un segundo, mientras que la falta de aire ocasiona la muerte a los 4 minutos, la ausencia de agua a los 4 días y la de los alimentos a los 60 (Gurdjieff, 2018, p. 98).

8 Una curandera ayuhasquera de una comunidad originaria de la selva amazónica peruana, recelosa de que los peruanos urbanos y los blancos extranjeros no pudieran "ver" si no ingerían en el periodo de dieta previo las hierbas indicadas para acceder a sus espíritus, comprobó con sorpresa que lograban ver. Al final se dio cuenta que esa gente extraña podía hacerlo porque disponía de la ayuda de otros espíritus, los de los libros (Belaunde, 2013). En general, toda la cultura y su consumo pueden ser interpretados en estos términos animistas. 
literarios, pero también a la cultura popular, principalmente al cine y a la literatura de consejos, e igualmente al ámbito de la empresa. Por otro lado, la narrativa terapéutica se relacionó también con el movimiento feminista, dando entre ambos una relevancia especial a la narración y evaluación de la intimidad sexual y emocional. Como consecuencia de todo lo anterior el yo se convirtió en algo cuantificable a partir de cierta métrica y lo íntimo se puso en discurso, todo lo cual eliminó el carácter volátil, efímero y contextual de las emociones, lo que permitió aislar las más "puras" y analizarlas en términos de coste-beneficio, lo cual, en último término, ha provocado la neutralización de su ambigua e indeterminada naturaleza. En el esfuerzo por controlar las emociones se inscribe también la autoayuda, cuyo primer precedente lo encontramos en 1859, con un libro de Samuel Smiles que relata casos de hombres que habían salido de la oscuridad y alcanzado fama y riqueza gracias a su volición y fuerza moral (Illouz, 2007: 93). En esta narrativa que privilegia el valor y la memoria del sufrimiento y del trauma fue activamente por el feminismo y más tarde lo terminaron de apuntalar los veteranos de Vietnam, que recibieron beneficios culturales y sociales por sus traumas. Luego ingresó en el campo del sufrimiento mental la potente industria farmacéutica y el no menos importante DSM (Diagnostical Statistical Manual), que desde 1954 comunica a los profesionales de la psique o alma con las grandes instituciones, privadas o públicas, de salud. Finalmente, en el capitalismo emocional han de incluirse también las redes sociales románticas, en Estados Unidos visitadas por entre 20 y 40 millones de personas por mes, lo que en el 2002 reportaba unas ganancias de 300 millones de dólares anuales (Illouz, 2007:165). En estas redes cada sujeto debe centrarse en su percepción de sí mismo, tener en cuenta que el conocimiento precede a la atracción, que el encuentro se organiza bajo la égida liberal de la libre elección y que Internet le coloca en competencia abierta con otros u otras. El resultado es que la racionalización de las emociones y del amor llegan a niveles sin precedentes que chocan con el pretendido carácter espontáneo, arrebatador, irracional, ensoñador, imaginativo, idealizador, etc. del amor.

En general, el tercer capitalismo toma los afectos de la vida anónima y ordinaria para pasar a convertirlos en una de las piedras angulares del nuevo orden social (Lordon, 2018). Sin embargo, los afectos tienen un carácter inicialmente ambivalente, efímero y escurridizo que no termina de desaparecer, más bien al contrario, una vez puestos en el centro de la existencia individual y colectiva. De ahí su parecido con la creatividad. En efecto, si esta preciada actividad tiene que ver con la capacidad de producir novedad, la cual es imprevisible, sus resultados han de ser también necesariamente indeterminados, como las propias emociones. Pues bien, para cierto filósofo presocrático, Anaximandro, el apeiron o lo indeterminado era el fundamento o arjé de todo y cierto pensamiento contemporáneo, principalmente en el ámbito de las ciencias duras, lo entiende también así. Por ejemplo, los físicos dicen que solo conocemos el $5 \%$ del Universo (el resto está formado por materias y energías oscuras), los exploradores de los genomas dicen que solo sabemos del sentido y función del $25 \%$ de las cadenas (el resto es ADN "basura") y respecto a lo social podríamos hablar del mismo modo (New Scientist, 2015; Thuan, 2018). En efecto, gran parte de la anodina vida cotidiana y de la actividad digital son invisibles e igualmente ocurre con los afectos y emociones en las que el bios se encarna. Pero es que la propia vida consciente de nuestra especie sobre el planeta solo nos es accesible a través de registros que prestan atención a la Historia, algo que solo ocurre desde hace 5000 años, con el comienzo del periodo dinástico egipcio, y que apenas ocupa un 5\% de la historia del sapiens sapiens, quedando el 95\% restante en la penumbra (Lachman, 2016, pp. 183-184). De modo que el apeiron o lo indeterminado, convertidos en la fuerza productiva principal o hegemónica en el capitalismo creativo, en realidad están presentes en cualquier orden de realidad.

La agencia que acoge lo indeterminado y desde la que se activa la capacidad de crear lo radicalmente nuevo es, otra vez, la vida colectiva en su máxima elementalidad, aunque 
ahora por debajo o al lado de las rutinas sociabilitarias y comunitarias del capitalismo anterior. Esta nueva agencia es lo imaginario. Su presencia en la creatividad de la vida cotidiana es algo que reconoce muy especialmente el negocio de la moda (Bergua, 2008), pues gran parte de él se inspira en las anónimas invenciones de detalles y composiciones que distintas clases de gentes realizan y pasean a diario, tanto por Internet (hasta alcanzar el nivel de influencers) como por las calles. Luego los cool hunters detectan lo que consideran más relevante, pasan esa información a las grandes firmas y estas hacen sus creaciones a partir de ella, incluso comprando influencers para divulgarlas por Internet, lo cual sirve de estímulo a las calles, entre otros agentes. Y así indefinidamente. En este ciclo autopoiético, la creatividad de abajo se basa en ingeniosos bricolajes y reutilizaciones que sacan los detalles de sus contextos, eliminan así sus valores de uso o cambio y crean valor estético?. Ya que en otros negocios creativos ocurre algo parecido, hay motivos para sospechar que la mayor parte de la creatividad de base excede a la más alta o visibilizada. Esto no debe sorprender pues fuera del ámbito de la creatividad también sucede que la actividad visible, computable, evaluable, etc. es mucho menor que la no filtrada. En efecto, por lo que respecta a Internet, como ya hemos visto, la Red Profunda es 9 veces mayor que la visible. Pero es que, además, los propios datos de la red visible son falsos, ya que hay ciertos bots (programas simuladores de la actividad humana en la Red) que aumentan artificialmente las visitas a algunos sitios, los cuales, de este modo, atraen más publicidad y beneficios. Se estima que entre el $20 \%$ y el $25 \%$ del tráfico de la red visible procede de estos impostores (Holmes, 2018). Si a esto sumamos la compra de seguidores falsos, asalta la duda acerca de la fiabilidad y futuro de los tan trabajados y solicitados big data. En definitiva, en el capitalismo gaseoso hay una actividad invisible tan importante como la que representa la Red Profunda en el capitalismo líquido de la información o del conocimiento y como la que expresa el trabajo informal o no mercantilizado en el capitalismo sólido o industrial. Dicha invisibilidad, además de inutilidad, también esconde grandes cantidades de utilidad no confesada o simplemente inadvertida.

En la mayor inmanencia o diferente plano respecto al bios en el que se mueve la creatividad se encuentra lo imaginario en tanto que magma de todos los sentidos habidos y por haber que luego aparecen como imaginario actualizado y más tarde se codifican y rutinizan hasta volverse incluso sólidas estructuras (Castoriadis, 1997; Cristiano, 2009). Por eso dice Spencer Brown (1994) que si algo existe es porque se ha imaginado la posibilidad de que exista. Esto también lo tenía muy claro el cristianismo primitivo -pues el mundo arquetipal, realidad primera y fundamental, solo resulta accesible a través de la imaginatio vera, que solo puede usarse a partir de imágenes que respetan el valor simbólico profundo (Riviere, 1998)-, el antiguo arte egipcio (con el que se pretendía manifestar la materia y regla universales, Maât, para actualizar el acto cosmogónico primordial) (Jacq, 1998), la Cábala (que accede al Dios oculto, En-Sof, o unidad indiferenciada e infinita, a través de una intrincada y dinámica red de símbolos que arranca en los 10 sefirots) (Elboudari, 1998), el sufismo (saber también oculto que presta atención al "mundo imaginal", que contiene las formas de todo lo que existe) (Corbin, 1993), etc. Pero es que las propias referencias de Marx al carácter fetichista de la mercancía, la aseveración de que en su tiempo un espectro (el comunismo) recorría Europa en busca de un cuerpo (el proletariado) en el que comenzar a realizarse y la no menor insistencia de Weber en la importancia del espíritu en el capitalismo, nos remiten a esa indeterminación imaginaria que el nuevo capitalismo ha convertido en su factor económico principal, del que extrae valor y plusvalía y al que devuelve sus outputs, creando así un ciclo de autopoiesis formalmente similar a los mencionados en los otros dos capitalismos.

\footnotetext{
9 Véase también McRobbie (1998), Uzzi y Spiro (2005), y Skov (2002). Esta creatividad informal de carácter horizontal y emergentista está tratada también, aunque desde otro punto de vista y prestando atención al jazz, por Becker (1982). En general, en relación a la creatividad informal de las gentes en la vida cotidiana, véase Certeau (1990). Por lo que respecta a la política de los movimientos sociales y tejidos asociativos véase Villasante (2006).
} 
Pues bien, si hacemos caso a Sloterdijk (2003), la agencia que tiene que ver con la manifestación de lo indeterminado a base de imaginación es ese quinto elemento del que hablaban los antiguos, el pneuma, y que tras el paso del cristianismo llamamos "espíritu". El autor alemán nos propone interpretar gran parte de la vida psíquica y colectiva en todas las escalas a partir de este concepto utilizando un discurso repleto de referencias a climas, atmósferas y otras metáforas gaseosas. La praxis política que pueda corresponder a este discurso bien podría derivar de los estados expandidos de conciencia y sociabilidad obtenidos, entre otras formas, con el consumo de enteógenos ${ }^{10}$. Las políticas y economías contemporáneas flirtean con todo ello para extraer más valor y poder con los que enriquecer sus circuitos de rentabilidad y dominio, pero también tratan con esta fuente las políticas y economías que pervierten y subvierten el orden instituido o simplemente o se resisten a él.

Las acciones prácticas políticas, económicas, etc. de esta tercera sociedad son transfinitas. Para entender esto es necesario acudir al origen matemático de esta noción (Warusfel, 1986, pp. 93-94). En general, la cantidad de elementos de un conjunto finito es menor que la cantidad de subconjuntos que se pueden formar con sus elementos. Aunque en el caso de los conjuntos infinitos parece que no es así, es fácil demostrar que existen por lo menos tantos subconjuntos como elementos tiene el conjunto, ya que por cada elemento del conjunto original habrá un subconjunto compuesto por solo ese elemento. Sin embargo, aquí nos encontramos con dos situaciones. Por un lado, están los conjuntos infinitos, cuyos elementos pueden ser puestos en correspondencia uno-a-uno con los números naturales. Estos conjuntos numerables se llaman aleph sub-cero $\left(\aleph_{0}\right)$ porque tienen aleph sub-cero elementos. Este es el primer transfinito. También caen dentro de este primer transfinito los conjuntos (más exactamente sus elementos) que establecen idéntica relación uno-a-uno con los números enteros y los racionales, pues no incrementamos realmente el número de objetos con los que trabajamos. Sin embargo, la situación cambia si hacemos entrar en escena los números reales, pues se puede demostrar que hay más números reales que racionales, por lo que los conjuntos de elementos asociados a aquella clase de números no son numerables. Aunque tal cosa no se ha podido asegurar del todo todavía, podemos especular que tales conjuntos tienen aleph sub-uno elementos o que estariamos ante el segundo transfinito $\left(\aleph_{1}\right)$. Del mismo modo, podríamos continuar pensando que hay un tercer infinito formado por conjuntos con más elementos que los números reales $\left(\aleph_{2}\right)$, también un cuarto transfinito $\left(\aleph_{3}\right)$, un quinto $\left(\aleph_{4}\right)$, etc. En definitiva, los "números" transfinitos hablan de clases y grados de infinitud.

En el campo de lo social se puede hacer referencia a tres mundos y registros de valor diferentes que guardan cierta relación con los números finitos, infinitos y transfinitos (Hartman y Ellis, 2015, pp. 93-109; Hartman, 1959, p. 226 y ss.). El mundo sistémico está formado por valores que se refieren a leyes y normas básicas, estructurales, sin las que quizás nada podría existir. Por ejemplo, en el caso del mundo occidental desarrollado, las leyes y normas que distinguen la política, la economía, el arte, etc. como ámbitos de acción distintos. El mundo extrínseco, por su parte, está compuesto por valores con un carácter unas veces horizontal y otras jerárquico, que relacionan a las gentes entre sí, con los objetos y con los entornos. Finalmente, el mundo intrínseco incorpora valores que ya no tienen que ver con la extensión del ente (como ocurre en el mundo extrínseco) sino con la intimidad del ser y que operan en profundidad.

Los valores sistémicos se refieren a una cantidad determinada y finita de propiedades, para las que no importan los grados, tan solo la existencia o la inexistencia de dichas propiedades. El valor extrínseco, por su parte, pone en relación a las personas entre sí o con las cosas en distintos ámbitos (política, economía, arte, etc.) donde los respectivos valores (poder, riqueza, estética, etc.) pueden ir de uno a infinito en sus distintas

10 En relación al uso de enteógenos (principalmente la ayahuasca y el San Pedro) como instrumento de lucha o resistencia política, véase Alvarado (2018). 
modalidades (fascista, comunista, democrático-social, democrático-liberal, etc., en la política; keynessiana, liberal, marxista, decrecentista, etc. en el caso de la economía; e impresionista, expresionista, vanguardista, postmodernista, etc. en el ámbito del arte; etc.). Finalmente, el valor intrínseco tiene que ver con el trato en profundidad con el respectivo Ser que cada valor extrínseco es capaz de alcanzar ${ }^{11}$.

La creatividad, en tanto que acontecimiento, es un fogonazo que tiene que ver con esta profundidad. Uno de los modos como se manifiesta es a través de la relación de dos valores extrínsecos diferentes. Es lo que ocurre con la "bisociación" (Koestler, 1975), que vincula, con la profundidad que la imaginación es capaz proporcionar y en un momento dado, dos marcos de pensamiento diferentes, cada uno capaz de albergar cierta infinitud, surgiendo de ese contraste el rayo creativo. El "pensamiento divergente" (Bono, 2006), otro modo de manifestarse la creatividad, también pone en relación dos marcos diferentes, pero en este caso no hay contraste especular, sino que el fogonazo surge de la disyunción. Si los marcos coincidieran, uno de ellos haría las veces de $\aleph_{0}$ respecto al otro y no habría creatividad. Por el contrario, si una infinitud fuera mayor que otra tendríamos al transfinito $\aleph_{1}$., que se referiría a un primer nivel o grado de creatividad. Lo transfinito también está presente en la psicología de Wilber (1989), quien añade a las esferas subpersonal o inconsciente y personal o consciente otra de carácter transpersonal o espiritual compuesta de varios estratos. Uno de ellos es el centáurico, del que precisamente resulta espontáneamente la creatividad, en el que el ego, el lenguaje y otros restos personales se difuminan, alcanzándose ese "estado flujo" (Csikszentmihalyi, 1996) que los creadores obtienen con sus actividades. En el último de tales estratos se alcanza un estado flujo más elevado o sutil y no dual de fusión mística con la totalidad. Finalmente, es también transfinita una operación que actúa en cualquier orden de realidad (físico, vivo, social, espiritual) y en cada uno de sus niveles, la transducción (Simondon, 1989). Aparece como consecuencia del desfase en el que un sistema está respecto a sus condiciones de existencia y se caracteriza por (re)incorporar aquello que perdió o dejó de lado al aparecer. Por ejemplo, si el sistema que llamamos Sociedad está formado por individuos, lo sagrado tiene que ver con lo transpersonal, término que en este caso designa el apeiron o indeterminación subjetiva que no ha cabido en el proceso de individuación personal o egoico y que ha de ser incorporado a un sistema posterior, aún por llegar, el cual generará un nuevo resto de apeiron o indeterminación, con otras propiedades, que también será incorporado a un nuevo sistema, etc. Como se ve, la transducción, del mismo modo que la bisociación o la divergencia es otro modo de hablar de la creatividad.

\section{DISCUSIÓN Y CONCLUSIONES}

La historia del capitalismo es la historia de tres factores productivos (el trabajo, la vida social ordinaria o bios y lo indetermimado o apeiron), en parte exteriores al sistema económico y en parte producidos por él. Cada uno de ellos ha sido objeto de explotación o de intercambio desigual por el capital, lo cual ha generado otros tantos antagonismos, con sus correspondientes discursos científicos y praxis políticas, a un lado, en medio y al otro de la línea de confrontación.

A medida que ha pasado de la explotación de un factor a otro, el capitalismo no solo ha engendrado lo instituido, sino un amplio abanico de potencias instituyentes, las cuales han tomado del mundo creado por cada modalidad de capitalismo los recursos con los que han

11 García Bacca (1984) se refiere a lo transfinito de otro modo. Partiendo del hecho de que el hombre es un animal que ha cultivado la finitud por el procedimiento de de-finir(se) o encerrar (se), puede suceder que el hombre descubra las infinitudes en las que sus respectivas finitudes flotan, lo cual permitirá que las finitudes se conviertan en metrónomos de dichas infinitudes. Si a ese gesto acompaña otro de las infinitudes por el que se dejan ser en sus respectivas finitudes, habrá sucedido que lo finito y lo infinito se habrán (re)acoplado. Lo transfinito apunta precisamente a eso. Facilitan este movimiento distintas clases de invenciones tecnológicas, geométricas, éticas, políticas, etc. que, en cada campo, permiten salir de los respectivos encierros. 
inventado sus resistencias, perversiones y subversiones. Así que el capital, en cualquiera de sus regímenes de explotación, es tanto fuente del orden como de conflicto, crisis y cambio. Eso sí, sin salir de los límites de lo posible.

Por cierto, las tres fases o etapas en las que el capital explota esos diferentes componentes del socius (la energía que aporta el trabajo, la información contenida en la sociabilidad ordinaria y el espíritu adherido a lo imaginario) son igualmente válidas para explicar la explotación de idénticas dimensiones de la zoé12 y de la fisis, pues también, en todos esos ámbitos, al principio, solo interesó la energía, ahora la información y no tardará en llegar el momento, si no ha llegado ya, en el que interese su imaginación o ánima.

Además de las resistencias, perversiones y subversiones interiores a los respectivos órdenes, hay también otra clase de resistencias, perversiones y subversiones que provienen del afuera de cada régimen y que, a diferencia de las interiores, no tienen expresión política ni discursiva, por mucho que algo se diga y se proponga hacer con ellas. Esta otra clase de disidencias tan solo sirve para tomar nota de que, más allá de los cambios, conflictos y crisis que se le resisten al orden, hay también un mundo imposible. Los vacíos o nada absolutos, en general y en cada una de las totalidades que el capitalismo ha creado, son homólogos a las nadas y vacíos detectados en los sistemas físicos (la materia y energía oscuras) y vivos (el ADN basura).

La búsqueda explícita y confesada de la explotación de la máxima elementalidad que desencadena el tercer capitalismo puede interpretarse como un "deseo" de reencuentro con lo que el segundo dejó de lado; en concreto, con lo imaginario e indeterminado que se despreció al elegir la vida colectiva ordinaria o bios como fuente de valor. Igualmente, el segundo capitalismo puede entenderse como un intento de recuperar lo que el primero no consideró, en este caso la vida ordinaria o bios del que el trabajo fue arrancado. En general, ambos gestos sugieren que el capital cambia de régimen para recuperar, transductivamente, parte de lo que en cada autoinstitución quedó como resto. Este insistente deseo de reunión o recuperación de lo que deliberadamente se dejó de lado o simplemente se perdió es lo que le hace "progresar" y el que crea campos reflexivos y políticos en los que pensar y ejecutar dicho cambio.

Sin embargo, es igualmente cierto que todo progresar a través del regreso siempre resulta fallido, pues con cada nuevo avance también se deja siempre algo nuevo detrás. Dicho de otro modo, saltando de una modalidad a otra y creciendo compulsivamente en cada una de ellas, los capitalismos no cesan de reproducir y aumentar la falta o falla con la que nacen. Esa falta o falla otro modo como se manifiesta la nada o vacío primordial.

Si el orden instituido por el capitalismo, busca recuperar una unidad que no cesa de frustrar, la pregunta es inevitable: ¿Será capaz lo social en su conjunto o en general de realizar absolutamente, de algún modo o desde alguno de sus ámbitos o esferas, ese insistente deseo que el capitalismo en cualquiera de sus variantes no cesa de alumbrar y de frustrar o habremos de permanecer siempre en una eterna cascada de transducciones, pues este estado es insuperable ${ }^{13}$ Por otro lado, ese deseo de (re)unión que se expresa

12 Vida nuda no humana, distinta de la vida nuda humana o bios (Agamben, 1998).

13 Martínez Marzoa (2018) ha propuesto una interpretación de los fundamentos ontológicos del capitalismo que podría proporcionar alguna respuesta. El filósofo entiende que la teoría del valor de Marx (para la que el trabajo abstracto es la fuente principal) es una ontología de la sociedad moderna ("todo cuanto es, es solo en la medida que es una mercancía” p. 141). Añade Martínez Marzoa que dicha ontología designa una encrucijada. En efecto, la revolución a la que la sociedad moderna está arrojada, no solo tiene que ver con la conservación de su fundamento revolucionario estructural (reducir todo a mero cálculo mercantil), sino también con el cumplimiento o finalización de su revolucionaria posibilidad (producirse a sí misma). Aventura Martínez Marzoa que el cumplimiento de la posibilidad, no solo tiene que ver con la realización del trabajo y de la igualdad, tal como el marxismo supone, sino con el inicio de lo ab-soluto en tanto que des-ligado de cualquier oposición. En el caso de Hegel lo que termina desligándose es la Razón Pura suprasensible. En el caso de Nietzsche lo que el nihilismo termina desligando es el Eterno Retorno. Dice Martínez Marzoa que Marx, sin saberlo, está más cerca de Nietzsche que de Hegel. En nuestra opinión, lo que se desliga es el apeiron y solo la anarquía puede tratar con ello. 
a través del capitalismo ¿es coherente con la necesidad de explotación y la inevitable producción de desigualdad social, devastación natural y empobrecimiento espiritual que protagoniza dicho modelo económico o, por el contrario, son incompatibles?

Para poder responder a esas preguntas, principalmente a la primera, quizás haya de asumirse antes que el capitalismo solo está dando forma a un deseo de re-encuentro con la totalidad de lo social que no cesa de fallar debido a que dicha totalidad excede al propio capitalismo. Tal totalidad engloba todos los órdenes instituidos por el capitalismo, solo o en alianza con otros impulsos, dando lugar a lo que en la Modernidad llamamos Sociedad, la cual incluye, además de su propio orden, un amplio abanico de desórdenes internos y vagas e imprecisas figuraciones de los imposibles vacíos exteriores. Pero la totalidad también abarca los órdenes, desordenes e imposibilidades que antecedieron a la Modernidad y los que le sucederán. Pues bien, las ciencias sociales y las políticas son poco capaces de pensar y gestionar lo social así entendido.

El juego de progresos y regresos que abren y colman fallas debe abordarse sociosóficamente (Bergua, 2017b). Un modo de hacerlo es interpretar esas idas y venidas en términos de muerte y renacimiento, utilizando para ello el amplio abanico de símbolos, mitos y ritos que desde tiempo inmemorial y en todas las culturas tratan del asunto (Bergua, 2019).

\section{REFERENCIAS}

Acemoglu, D. y Robinson, J. A. (2012). Por qué fracasan los países. Barcelona: Ediciones Deusto, Grupo Planeta.

Agamben, G. (1998). Homo Sacer. El poder soberano y la nuda vida. Valencia: Pre-Textos.

Alvarado, N. (2018). El conflicto amazónico Bagua 2008-2009. La confrontación entre las cosmovisiones del pueblo Awajún-Wampis y el poder político y económico del Perú (Tesis doctoral). Universidad de Zaragoza, Departamento de Psicología y Sociología, Zaragoza.

Arroyo Guardeño, D., Díaz Vico, J. y Hernández Encinas, L. (2019). Blockchain. Madrid: CSIC/ La Catarata.

Atlan, H. (1990). Entre el cristal y el humo. Madrid: Debate.

Badiou, A. (1990). ¿Es posible la política? Buenos Aires: Nueva visión.

Badiou, A. (1999). Ser y acontecimiento. Buenos Aires: Manantial.

Bauman, Z. (1997). Modernidad líquida. Buenos Aires: FCE.

Becker, H. S. (1982). Art Worlds. Los Angeles: University of California Press.

Belaunde, L. E. (2013). Entrevista con Herlinda Agustín, mujer onaya del pueblo shipibokonibo. En B. Caiuby Labate y J. C. Bouso (eds.), Ayahuasca y salud (pp. 48-65). Barcelona: La Liebre de Marzo.

Bell, D. (2006). El advenimiento de la sociedad postindustrial. Madrid: Alianza.

Bergua, J. A. (2008). Diseñadores, tribus y coolhunting. Una aproximación sociológica a la creatividad en el ámbito de la moda. Revista Española de Investigaciones Sociológicas, (124), 45-71.

Bergua, J. A. (2017a). Creatividad. Un objeto sociológico límite. En C. Sánchez Capdequí (ed.), La creatividad social: narrativas de un concepto actual (pp. 423-459). Madrid: CIS. 
Bergua, J. A. (2017b). Sociosofía. Barcelona: Anthropos.

Bergua, J. A. (2019). Creatividad y muerte. Trabajo presentado en XIII Seminario Hispano Argentino: Genealogía de la creatividad, San Vicente del Raspeig, España.

Bergua, J. A., Carretero, E., Báez, J. M. Y Pac, D. (2016). Creatividad. Números e imaginarios. Madrid: CIS

Boltanski, L. y Chiapello, E. (2002). El nuevo espíritu del capitalismo. Madrid: Akal.

Bono, E. de (2006). El pensamiento lateral. Barcelona: Paidós.

Castells, M. (1996). La ciudad informacional. Madrid: Alianza.

Castoriadis, C. (1997). Fait el á faire. Les carrefours du labyrinthe. Paris: Seuil.

Castro Martínez, E. y Fernández de Lucio, I. (2013). El significado de innovar. Madrid: CSIC/ La Catarata.

Certeau, M. de (1990). L'invention du quotidien, 1. Arts de faire. Paris: Gallimard.

Corbin, H. (1993). La imaginación creadora en el sufismo de Ibn Arabi. Barcelona: Destino.

Cristiano, J. (2009). Imaginario instituyente y teoría de la sociedad. Revista Española de Sociología, 11, 101-120.

Csikszentmihalyi, M. (1996). Creativity: Flow and the Psychology of Discovery and Invention. New York: Harper Perennial.

Donegan, M. y Lowe, N. (2008). Inequality in the Creative City: Is There Still a Place for ‘Old-Fashioned' Institutions? Economic Development Quarterly, 22(1), 46-62. http://doi. org/10.1177/0891242407310722

Dupuy, J. P. (1992). Introduction aux sciences sociales. Logique des phénomènes collectives. Paris: Ellipses.

Elboudari, H. (1998). Démons. Judaisme. En J. Servier (ed.), Dictionaire critique de l'esoterisme (pp. 391-393). Paris: Puf.

Florida, R. (2002). The Rise of the Creative Class. New York: Basic Books.

Florida, R. (2017). The urban crisis. New York: Basic Books.

Fumagalli, A. (2010). Bioeconomía y capitalismo cognitivo. Madrid: Traficantes de Sueños

Gaggi, M. y Naduzzi, E. (2006). El fin de la clase media y la sociedad de bajo coste. Madrid: La Lengua de Trapo.

García, J. L. (2012). El discurso de la innovación en tela de juicio: tecnología, mercados y bienestar humano. Arbor, 188, 73. https://doi.org/10.3989/arbor.2012.753n1002

García, J. L. (2014). La "crisis" y la metamorfosis del capitalismo. Revista Española de Sociología, 22, 145-161.

Goldstein, R. (2005). Gödel. Paradoja y vida. Barcelona: Antoni Bosch.

García Bacca, J. D. (1984). Infinito, transfinito, finito. Barcelona: Anthropos.

Goldthorpe, J. (1993). Sobre la clase de servicio: su formación y su futuro. En J. Carabaña y Francisco A. de (eds.), Teorías contemporáneas de clases sociales (pp. 229-263). Madrid: Fundación Pablo Iglesias.

Gurdjieff, G. I. (2018). En busca del Ser. El Cuarto Camino hacia la conciencia. Barcelona: La Llave. 
Hardt, M. y Negri, T. (2000). Imperio. Cambridge: Harvard University Press.

Hartman, R. S. (1959). La estructura del valor. México: FCE.

Hartman, R. S. y Ellis, A. R. (2015). Libertad para vivir. La historia real de Robert. S. Hartman. Barcelona: La Liebre de Marzo.

Heisenberg, W. (1988). La imagen de la naturaleza en la física actual. Barcelona: Orbis.

Holmes, D. E. (2018). Big Data. Barcelona: Antoni Bosch.

Howkins, J. (2005). The Creative Economy. How People make Money from Ideas. Londres: Penguin Books.

Illouz, E. (2007). Intimidades congeladas. Buenos Aires: Katz.

Khor, M. (2001). La globalización desde el Sur. Barcelona: Icaria.

Klein, N. (2001). No logo. Barcelona: Paidós

Jacq, C. (1998). Art. Égypte pharaonique. En J. Servier (ed.), Dictionaire de l'ésotérisme (pp. 137-138). Paris: PUF.

Koestler, A. (1975). The act of Creation. London: Picador.

Lachman, G. (2016). Una historia secreta de la conciencia. Girona: Atalanta.

Latour, B. (1992). Nous n'avons jamais été modernes. Paris: La Découverté.

Laval, C. y Dardot, P. (2015). Común. Barcelona: Gedisa.

Lordon, F. (2018). La sociedad de los afectos. Por un estructuralismo de las pasiones. Buenos Aires: Adriana Hidalgo.

Marimón, C. (2020). La creatividad. Genealogía y contextos sociales de un término (muy) reciente en español. Tonos digital, 38. Manuscrito presentado para su publicación.

Martínez Marzoa, F. (2018). La filosofía del Capital. Madrid: Abada.

Marx, K. (1971). El Capital. México: FCE.

Mason, P. (2016). Postcapitalismo. Barcelona: Paidós.

McRobbie, A. (1998). British Fashion Design. Rag Trade or Image Industry? Londres: Routledge.

Mould, O. (2019). Contra la creatividad. Madrid: Alfabeto.

New Scientist. (2015). Nada. Del cero absoluto al olvido cósmico. Reflexiones insólitas acerca de la nada. Madrid: Alianza.

Ortiz-Osés, A. (1993). Las claves simbólicas de nuestra cultura. Matriarcalismo, patriarcalismo y fratriarcalismo. Barcelona: Anthropos.

Pettifor, A. (2017). La producción del dinero. Barcelona: Sin Fronteras.

Piketty, T. (2014). El capital en el siglo XXI. México: FCE.

Pine, B. J. y Gilmore, J. H. (2000). La economía de la experiencia. Madrid: Granica.

Prigogine, I. y Stengers, I. (1990). La nueva alianza. La metamorfosis de la nueva ciencia. Madrid: Alianza.

Riviere, P. (1998). Archétype. Christianisme primitive. En J. Servier (ed.), Dictionaire de l'ésotérisme (pp. 125-126). Paris: PUF.

Sadin, E. (2018). La siliconización del mundo. Buenos Aires: Caja Negra. 
Simondon, G. (1989). L'individuation psychique et collective. París: Aubier.

Skov, L. (2002). Hong Kong Fashion Designers as Cultural Intermediaries. Out of Global Garment Production. Cultural Studies, 16(4), 553-569. https://doi.org/10.1080/09502380210139115

Sloterdijk, P. (2003). Esferas I. Madrid: Siruela.

Soto, H. de (2000). El misterio del capital. Por qué el capitalismo triunfa en Occidente y fracasa en el resto del mundo. México: Diana.

Spencer Brown, G. (1994). Laws of Form. Portland: Cognizer.

Srnicek, N. (2018). Capitalismo de plataformas. Buenos Aires: Caja Negra.

Standing, G. (2011). El precariado. Una nueva clase social. Madrid: Capitán Swing.

Taleb, N. N. (2008). El cisne negro. El impacto de lo altamente improbable. Barcelona: Paidós.

Thuan, T. X. (2018). La plenitud del vacío. Barcelona: Kairós.

Uzzi, B. y Spiro, J. (2005). Collaboration and creativity. American Journal of Sociology, 76(2), 262-272. https://doi.org/10.1086/432782

Verdú, V. (2003). El estilo del mundo. Barcelona: Anagrama.

Villasante, T. R. (2006). Desbordes creativos. Estilos y estrategias para la transformación social. Madrid: La Catarata.

Virno, P. (2003). Gramática de la multitud. Madrid: Traficantes de Sueños.

Warusfel, A. (1986). Las matemáticas modernas. Barcelona: Orbis.

Wilber, K. (1989). El proyecto Atman. Barcelona: Kairós.

Wright, E. O. (1994). Clases. Madrid: Siglo XXI.

\section{NOTA BIOGRÁFICA}

José Angel Bergua Amores es catedrático de Sociología en la Facultad de Economía y Empresa de la Universidad de Zaragoza. Ha investigado y escrito sobre la juventud, los conflictos medioambientales, la creatividad, la crisis de la occidentalidad y diversas cuestiones teóricas y metodológicas relacionadas con el desorden, lo imaginario, las anamnesis, lo sagrado y, en general, la potencia instituyente de lo social. Además de artículos en revistas especializadas y capítulos en obras colectivas ha publicado: La gente contra la sociedad. Impacto sociocultural de un divertimento juvenil (2002), Los Pirineos y el conflicto del agua (2003), Patologías de la modernidad (2005 y 2019), Lo social instituyente. Materiales para una sociología no clásica (2007), Anarquías. Ámbitos no jerárquicos de lo social, (2013) Estilos de la Investigación social. Técnicas, epistemología, algo de anarquía y una pizca de sociosofía (2011 y 2018), Postpolítica. Elogio del Gentío (2015) y Sociosofía (2017). También ha dirigido: Coolhunting. Diseñadores y multitudes creativas en Aragón (2007), Reinventar los Pirineos. A propósito del conflicto del oso (2010) y Creatividad. Números e Imaginarios (2016). 